ORIGINAL ARTICLE

\title{
Field and laboratory testing in young elite soccer players
}

\author{
K Chamari, Y Hachana, Y B Ahmed, O Galy, F Sghaïer, J-C Chatard, O Hue, U Wisleff
}

Br J Sports Med 2004;38:191-196. doi: 10.1136/bjsm.2003.004374

See end of article for authors' affiliations

.....................

Correspondence to: Dr Wisløff, Department of Circulation and Medical Imaging, Norwegian University of Science and

Technology, Olav Kyrres gt

3, 7489 Trondheim

Norway; ulrik.wisloff@

medisin.ntnu.no

Accepted 11 March 2003

\begin{abstract}
Aim: To determine if there are correlations between the physical fitness of young soccer players assessed by field and laboratory testing.

Methods: Thirty four male soccer players took part in the study (mean (SD) age 17.5 (1.1) years, height $177.8(6.7) \mathrm{cm}$, weight $70.5(6.4) \mathrm{kg})$. Maximal oxygen uptake $\left(\mathrm{VO}_{2} \mathrm{MAX}\right)$ during treadmill running and vertical jump height on a force plafform were measured in the laboratory. Field tests consisted of a soccer specific endurance test (Bangsbo test) and $30 \mathrm{~m}$ sprint with $10 \mathrm{~m}$ lap times.

Results: The Bangsbo test correlated with the lowest velocity associated with $\mathrm{VO}_{2} \mathrm{MAX}\left(V \mathrm{VO}_{2} \mathrm{MAX} ; R^{2}=0.55\right.$, $\mathrm{p}<0.001$ ), but not with $\mathrm{VO}_{2} \mathrm{MAX}$. Sprint times at $30 \mathrm{~m}$ and $20 \mathrm{~m}$ were related to peak extension velocity and peak extension force measured during vertical jumping, but not to vertical jump height per se. The jumping force and velocity could explain $46 \%$ of the $30 \mathrm{~m}$ sprint performance $\left(R^{2}=0.46, p<0.001\right)$.

Conclusion: The Bangsbo test and $30 \mathrm{~m}$ sprint test correlate with $\mathrm{vVO}_{2} \mathrm{MAX}$ and vertical jump force and velocity respectively. The Bangsbo test does not give a good estimate of $\mathrm{VO}_{2} \mathrm{MAX}$ in young soccer players.
\end{abstract}

$\mathrm{T}$ echnical and tactical skills in soccer are highly dependent on the player's physical capacity. ${ }^{12}$ More than $90 \%$ of a game is performed by aerobic metabolism, ${ }^{1}$ and the average intensity is around the anaerobic lactate threshold (80-90\% of maximal heart rate). ${ }^{13}$ However, the actual time spent at exactly that intensity is about 20 minutes, as the players either exercise above (accumulating lactate) or below (oxidising the accumulated lactate) this threshold. ${ }^{3}$ One of the most important factors that influence exercise intensity is the player's maximal oxygen uptake $\left(\mathrm{VO}_{2} \mathrm{MAX}\right)$. A recent study showed that increasing $\mathrm{VO}_{2} \mathrm{MAX}$ by $11 \%$ increased match intensity by $5 \%$ and distance covered in a match by $1800 \mathrm{~m} .^{3}$ The third variable that influences a player's aerobic endurance performance is running economy. Hoff et $a l^{2}$ estimated that an improvement in running economy by $5 \%$ would increase the distance covered in a match by about $1000 \mathrm{~m}$. Both anaerobic threshold and running economy have been shown to be increased by increased $\mathrm{VO}_{2} \mathrm{MAX} .{ }^{3}$ Whereas evaluation of the first two variables requires laboratory tests, there are several field tests to assess an athlete's $\mathrm{VO}_{2} \mathrm{MAX}^{4}{ }^{4}$ Recently, Kemi et al ${ }^{6}$ showed that it is possible to reach $\mathrm{VO}_{2} \mathrm{MAX}$ in a soccer specific test with the ball. However, this requires a portable gas analyser, not available for most teams. Specific field tests have been designed to assess endurance specific to soccer players, ${ }^{7-9}$ but, to our knowledge, none has been shown to be directly correlated with the classical $\mathrm{VO}_{2} \mathrm{MAx}$ laboratory treadmill test. The Bangsbo $^{1810}$ intermittent field test is easy to perform and mimics the highest intensities experienced during a soccer match. It is acceptable to players because of its movement similarities to soccer, and the test is routinely used to assess soccer specific endurance..$^{1810-12}$ One goal of the present study was to determine whether the results from the Bangsbo test reflect the subject's $\mathrm{VO}_{2} \mathrm{MAX}$.

Although most of the game is aerobic, the most decisive skills, such as the ability to jump high and sprint fast in duels against opponents, are anaerobic. ${ }^{1}$ Wisløff et $a l^{13}$ showed a strong correlation between maximal muscle strength, vertical jump performance, and 10-30 m sprint times in well trained male elite soccer players. Whether this relation also exists in younger, less well trained soccer players is not known. The main tests for measuring force, power, and sprint in soccer players are the vertical jump on a force platform ${ }^{14}{ }^{15}$ and the 10-30 m sprint. ${ }^{13} 16$

The major hypothesis of this study was that the results from the Bangsbo test reflect the $\mathrm{VO}_{2} \mathrm{MAX}$ of young soccer players. In addition, we determined whether there is a relation between the power abilities - that is, vertical jump performance measured on a force platform-and the 10$30 \mathrm{~m}$ sprint time.

\section{MATERIALS AND METHODS \\ Subjects}

Thirty four male soccer players volunteered to participate in the study and provided written informed consent in accordance with the Declaration of Helsinki. The university ethics committee approved the study protocol. The subjects could withdraw from the study at any time. Their physical characteristics were as follows (mean (SD)): age 17.5 (1.1) years; height 177.8 (6.7) cm; weight 70.5 (6.4) kg; body mass index $22.5(1.4) \mathrm{kg} / \mathrm{m}^{2}$; percentage body fat $11.8(2.0)$. Percentage body fat was calculated according to the formula of siri based on four skinfold measurements (biceps, triceps, subscapularis, and suprailiac). ${ }^{17}$ Twenty two of the subjects were members of the Tunisian national under 19 team, and the remaining 12 belonged to one of the best three ranked teams in Tunisia during the last 10 years. The latter composed the elite players of the club and lived in a special "centre of excellence" included in the club's infrastructure. Seven of these 12 players were recruited from Senegal three months before the experiment. The subjects were informed about the test protocols, without being informed about the aim of the study. They participated in the national soccer championship as regular players, and some of them were selected for the senior team of their respective clubs. At the time of the experiment, their average weekly training programmes included $8-10$ training sessions a week (each session lasting about 90 minutes), mainly soccer training and very rarely on track running or muscular strength training.

The experiment was performed mid-season-that is, three to five months after the beginning of the competitive season. The cohort studied was comprised four goalkeepers, 12 defenders, 12 midfield players, and six forwards. 


\section{Test protocols}

Owing to injuries and the busy programme of some of the players, not all the subjects were able to perform all the tests. Each player was tested separately, instructed, and verbally encouraged to give maximal effort on all the tests. The number of players who took part in the different tests is presented in the tables and figures.

\section{Laboratory testing}

Laboratory testing was performed between 2 and $5 \mathrm{pm}$ (mean (SD) ambient temperature $21(1)^{\circ} \mathrm{C}$ ) on two days, separated by one week. The subjects were wearing shorts and running shoes. They had been asked to abstain from exercise the day before the tests and not to drink caffeine-containing beverages on the day of the tests.

\section{Day 1}

On entering the laboratory, subjects lay on a bench and rested for 15 minutes. The lowest heart rate during that period was recorded. They then ran on a flat treadmill (Ergo XELG 90; Woodway, Weil, Germany) for three minutes at $9 \mathrm{~km} / \mathrm{h}$. The speed was then increased by $1 \mathrm{~km} / \mathrm{h}$ every minute until exhaustion, which occurred within 10-15 minutes for all subjects. The following criteria were met by all players when $\mathrm{VO}_{2} \mathrm{MAX}$ was tested: $(a)$ a levelling off of $\mathrm{VO}_{2}$ despite an increase in treadmill speed; $(b)$ a respiratory gas exchange ratio higher than $1.1 ;(c)$ blood lactate higher than $6 \mathrm{mmol} / \mathrm{l}$. The highest heart rate attained at exhaustion was recorded. Cardiorespiratory variables were determined using a breath by breath system (ZAN 680; Messgeräte, Oberthulba, Germany) allowing continuous measurement of heart rate, oxygen uptake, and lung ventilation. Before each test, the gas analysers were calibrated with gasses of known concentration, and the ventilatory membrane was calibrated with a I litre syringe. Heart rate was determined from a six lead electrocardiograph with 12 derivations. Heart rate and respiratory data were recorded once every 30 seconds, with the values averaged over the last 10 respiratory cycles on a sliding technique basis. ${ }^{18}$ The lowest and highest velocity associated with $\mathrm{VO}_{2} \mathrm{MAX}\left(v \mathrm{VO}_{2} \mathrm{MAX}\right.$ and vpeak $\mathrm{VO}_{2} \mathrm{MAX}$ respectively) were established as described by Billat and Koralsztein $^{19}$ and Paavolaïnen et $a l_{,}{ }^{20}$ and respiratory compensation threshold $\left(\mathrm{Th} 2_{\mathrm{vent}}\right)$ as described by Beaver et al. ${ }^{21}$ If $\mathrm{VO}_{2} \mathrm{MAX}$ is expressed as $\mathrm{ml} / \mathrm{kg} / \mathrm{min}$, the work capacity of light subjects is overestimated and that of heavy subjects is underestimated. ${ }^{15}$ Consequently, Bergh et al, ${ }^{22}$ Wisløff et al, ${ }^{15}$ Helgerud $e t a l^{3}$ and Hoff $e t a l^{2}$ have expressed oxygen uptake as $\mathrm{ml} / \mathrm{kg}^{0.75} / \mathrm{min}$ for comparisons among athletes and soccer players of different body mass. Indeed, $\mathrm{VO}_{2} \mathrm{MAX}$ does not increase in direct proportion to body mass. ${ }^{22}$ Dimensional scaling of geometrically similar subjects suggests that the cross section area of the aorta will increase in proportion to the square of the height $\left(\mathrm{L}^{2}\right)$ whereas body mass is dependent on body volume, which varies according to $\mathrm{L}^{3}$. Consequently, $\mathrm{VO}_{2} \mathrm{MAX}$, which is primarily limited by maximal cardiac output, should be proportional to body mass $\left(\mathrm{m}_{\mathrm{b}}\right)$ raised to the power of $0.67\left(\mathrm{~m}_{\mathrm{b}}{ }^{0.67}\right)$. This dimensional scaling approach was supported by Bergh et al, 22 who found that $\mathrm{VO}_{2} \mathrm{MAX}$ relative to body mass raised to the power of 0.75 was indicative of performance capacity in running. Despite the fact that the theoretically correct $\mathrm{m}_{\mathrm{b}}{ }^{0.67}$ should be used, most published papers on soccer players have used the $\mathrm{ml} / \mathrm{kg}^{0.75}$ / min expression. Wisløff et al ${ }^{15}$ suggested that expressing $\mathrm{Vo}_{2}$ MAX in relation to $\mathrm{m}_{\mathrm{b}}{ }^{0.67}$ or $\mathrm{m}_{\mathrm{b}}{ }^{0.75}$ may not be critical as long as the unit approximates the theoretical value and not the traditional $\mathrm{m}_{\mathrm{b}}$. Dimensional scaling should ideally be based on fat-free mass, because fat has very low metabolic activity. ${ }^{23}$ In the present study the statistical outcome of using fat-free body mass or body mass was similar (data not shown). We chose to use dimensional scaling based on body mass so that we could directly compare our results with previous studies. ${ }^{3} 131524$

\section{Day 2}

The vertical jump was performed from a fixed semisquat position with the hands fixed at the hips using a force platform (9281 C; Bioware, Kistler, Switzerland). Each player performed three jumps with two minutes of rest in between, and the best jump was selected for analysis. Peak jumping force $\left(\mathrm{F}_{\text {peak }}\right)$, peak jumping velocity $\left(\mathrm{v}_{\text {peak }}\right)$, peak jumping anaerobic power $\left(\mathrm{W}_{\mathrm{an}}\right)$, and the peak height of the jump $\left(\mathrm{H}_{\text {peak }}\right)$ were recorded. After this procedure, the subject also performed a free counter movement jump protocol. The statistical results were similar using data from these two tests, and for clarity we chose to present only the former in this paper.

As for the $\mathrm{VO}_{2} \mathrm{MAx}$ expression, dimensional scaling must also be considered when evaluating strength measures. ${ }^{15}$ In two geometrically similar and quantitatively identical individuals, one may expect all linear dimensions (L) to be proportional. The length of the arms, the legs, and the individual muscles will have a ratio of $\mathrm{L}: 1$, the cross sectional area $L^{2}: 1$, and the volume ratio $L^{3}: 1$. As muscular strength is directly proportional to the muscle cross sectional area, and body mass $\left(\mathrm{m}_{\mathrm{b}}\right)$ varies directly with body volume, whole body muscular strength measures will vary in proportion to $\mathrm{m}_{\mathrm{b}}{ }^{0.67}$. The peak force is therefore expressed as $\mathrm{N} / \mathrm{kg}^{0.67}$.

\section{Field testing}

All field tests were performed on one day, one week after the end of the laboratory testing. The sprint tests were performed in the morning and the Bangsbo test in the afternoon. The tests were performed on a natural grass soccer pitch, and the subjects were wearing soccer kit. During the non-raining field test days, wind speed did not exceed 8 knots $(4.11 \mathrm{~m} / \mathrm{s})$ and air temperature ranged from $23^{\circ} \mathrm{C}$ to $26^{\circ} \mathrm{C}$.

\section{0 m sprint}

The subjects performed 20 minutes of individual warm up including several accelerations knowing that they had to choose which foot they had to put on the starting line for the sprint standing position start. They then performed three $30 \mathrm{~m}$ sprints including $10 \mathrm{~m}$ lap timing with three minutes of recovery in between. Speeds were measured with infrared photoelectric cells (Matsport timing BTS, Seyssinet, France) positioned at exactly 10 and $30 \mathrm{~m}$ from the starting line at a height of $1 \mathrm{~m}$. The $20 \mathrm{~m}$ (from the $10 \mathrm{~m}$ to the $30 \mathrm{~m}$ line) performance was then calculated. The stopwatch starting pedal was positioned behind the starting line. The subject had to start from a standing position placing his forward foot just behind the starting line and his rear foot on the pedal after having positioned the pedal according to his natural starting position. The timing started as soon as the foot of the player left the pedal. Before testing, each subject performed a submaximal sprint to familiarise himself with the test procedure. The sprint resulting in the best $30 \mathrm{~m}$ performance was selected for analysis.

\section{The Bangsbo test}

This soccer specific endurance test was proposed by Bangsbo and Lindquist ${ }^{7}$ and further described by Bangsbo. ${ }^{8}{ }^{10}$ Figure 1 illustrates the test track. Briefly, the test lasts 16.5 minutes, during which players alternate between 40 bouts of high intensity exercise each lasting 15 seconds and 40 bouts of low intensity exercise each lasting 10 seconds. The work-rest periods were dictated by one long sound signal for the beginning and two short sound signals (whistle) at the end of each sprint. During the high intensity periods, the subjects 
A

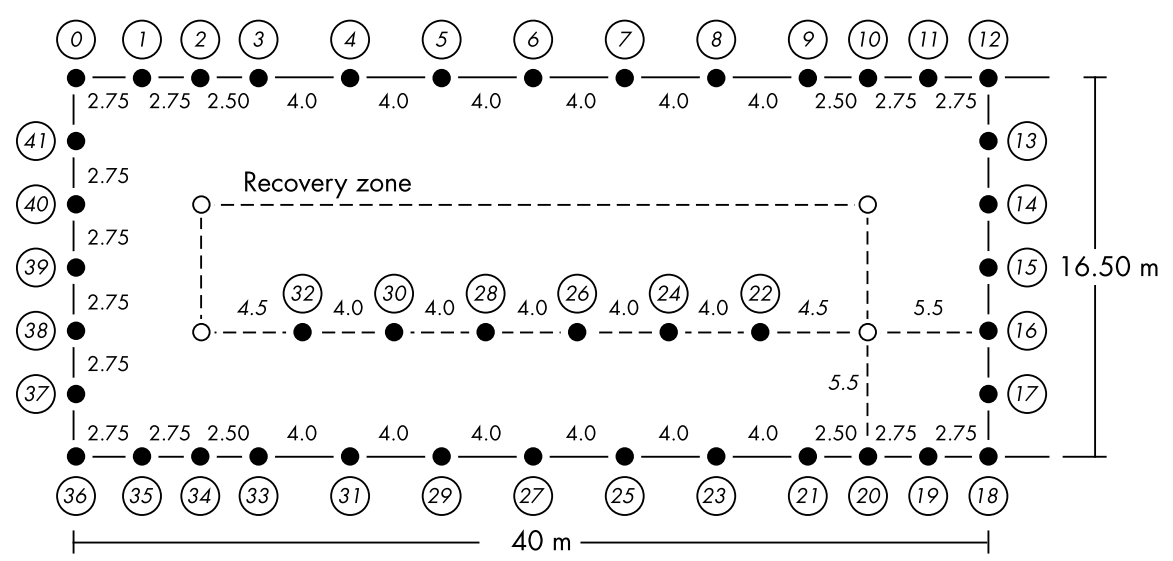

Coloured cones: (15) (21) (33) (39)

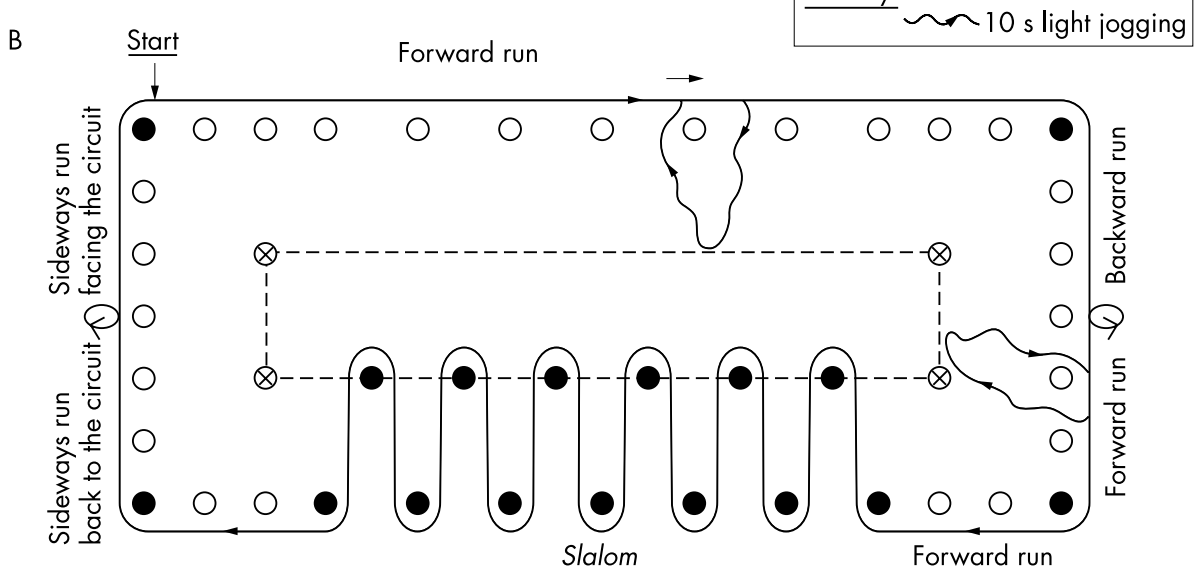

Figure 1 The Bangsbo soccer field test circuit. (A) Circuit dimensions. The length and width of the circuit correspond to that of the penalty area of a soccer pitch. The recovery zone is delimited by four small cones at the corners and wooden battens on the field. Cones 15 and 39 correspond to running direction changes, and cones 21 and 33 to the beginning and end of the slalom. They should be of different colour to be easily identified. The four cones at the area corners $(0,12,18$, and 36) and the slalom cones (21-33) must be at least $1.2 \mathrm{~m}$ high. The others can be small cones. (B) The test lasts 16.5 minutes, during which players alternate between 4015 second bouts of high intensity exercise and 10 second low intensity exercise jogs. During the high intensity periods, subjects follow the $160 \mathrm{~m}$ circuit, running $40 \mathrm{~m}$ forward, $8.25 \mathrm{~m}$ backwards, $95.25 \mathrm{~m}$ forward and through a $120^{\circ}$ angle slalom, $8.25 \mathrm{~m}$ sideways while facing away from the centre of the circuit, and $8.25 \mathrm{~m}$ sideways while facing the centre of the circuit. During the low intensity periods, players jog to the centre of the circuit and back to the last cone marked position they reached at the end of the previous high intensity period. If the sound signal stops them during the slalom, the low jogging is performed towards the next slalom cone and back to the last cone they reached before the signal. The test performance is the distance covered during the 40 periods of high intensity running.

follow an outlined circuit around the penalty area of a soccer field. They run $40 \mathrm{~m}$ forward, $8.25 \mathrm{~m}$ backwards, $95.25 \mathrm{~m}$ forward and through a $120^{\circ}$ angle slalom, $8.25 \mathrm{~m}$ sideways while facing away from the centre of the circuit, and $8.25 \mathrm{~m}$ sideways while facing the centre of the circuit. During the low intensity periods, players jog to the centre of the circuit and back to the last cone marked position they reached at the end of the previous high intensity period. The test performance is the distance covered during the 40 periods of high intensity running. Before each test, after 10 minutes of standardised warm up, the players had 10 minutes to familiarise themselves with the circuit by light jogging. They then had to try the test pace-that is, the 15 second high intensity and 10 second light intensity bouts of exercise-for four minutes. This allowed them to find a personal running pace to try to perform the best performance over the 16.5 minute test duration. After the warm up and the familiarisation, they rested for 10 minutes before performing the test. During the Bangsbo test, heart rate was monitored with a heart rate monitor (Polar S-610; Polar

\begin{tabular}{|c|c|c|c|c|c|c|c|c|}
\hline & \multicolumn{3}{|c|}{$\mathrm{Vo}_{2} \operatorname{MAX}$} & \multirow{2}{*}{$\begin{array}{l}\mathrm{vVO} \mathrm{O}_{2} \operatorname{MAX} \\
(\mathrm{km} / \mathrm{h})\end{array}$} & \multirow{2}{*}{$\begin{array}{l}V_{\text {peak }} V_{O_{2}} \text { MAX } \\
(\mathrm{km} / \mathrm{h})\end{array}$} & \multirow{2}{*}{$\begin{array}{l}\text { Th2 } 2_{\text {vent }} \\
\left(\% \mathrm{VO}_{2} \text { MAX) }\right.\end{array}$} & \multirow{2}{*}{$\begin{array}{l}\text { HRMAX } \\
\text { (beats/min) }\end{array}$} & \multirow{2}{*}{$\begin{array}{l}\left.\text { Peak [ } \mathrm{La}^{-}\right] \\
\text {(mmol/l) }\end{array}$} \\
\hline & $1 / \min$ & $\mathrm{ml} / \mathrm{kg} / \mathrm{min}$ & $\mathrm{ml} / \mathrm{kg}^{0.75} / \mathrm{min}$ & & & & & \\
\hline $\begin{array}{l}\text { Mean } \\
\text { SD }\end{array}$ & $\begin{array}{l}4.3 \\
0.4\end{array}$ & $\begin{array}{l}61.1 \\
4.6\end{array}$ & $\begin{array}{l}177 \\
13\end{array}$ & $\begin{array}{l}18.4 \\
10\end{array}$ & $\begin{array}{l}19.0 \\
0.9\end{array}$ & $\begin{array}{l}90.1 \\
3.9\end{array}$ & 191 & 11.6 \\
\hline
\end{tabular}

$\checkmark \mathrm{VO}_{2} \mathrm{MAX}$, Lowest velocity associated with $\mathrm{VO}_{2} \mathrm{MAX} ; v_{\text {peak }} \mathrm{VO}_{2} \mathrm{MAX}$, highest velocity attained before exhaustion; Th2 $2_{\text {vent, }}$ second ventilatory threshold or compensation respiratory threshold expressed as percentage of $\mathrm{VO}_{2} \mathrm{MAX} ; \mathrm{HRMAX}$ maximum heart rate; [ $\mathrm{La}^{-}$], lactate concentration. 
Table 2 Main vertical jumping results measured on a force platform in the laboratory $(n=30)$

\begin{tabular}{|c|c|c|c|c|c|c|c|c|c|}
\hline & \multicolumn{3}{|l|}{$W_{\mathrm{an}}$} & \multicolumn{3}{|l|}{$F_{\text {peak }}$} & \multirow[b]{2}{*}{$\operatorname{TPF}(s)$} & \multirow[b]{2}{*}{$\begin{array}{l}v_{\text {peak }} \\
(\mathrm{m} / \mathrm{s})\end{array}$} & \multirow{2}{*}{$\begin{array}{l}\text { Jump } \\
\text { height } \\
\text { (cm) }\end{array}$} \\
\hline & W & $\begin{array}{l}\text { W/ } \\
\text { kg }\end{array}$ & $\begin{array}{l}\mathrm{W} / \\
\mathrm{kg}^{0.67}\end{array}$ & $\mathrm{~N}$ & $\begin{array}{l}\mathrm{N} / \\
\mathrm{kg}\end{array}$ & $\begin{array}{l}\mathrm{N} / \\
\mathrm{kg}^{0.67}\end{array}$ & & & \\
\hline $\begin{array}{l}\text { Mean } \\
\text { SD }\end{array}$ & $\begin{array}{l}3878 \\
553\end{array}$ & $\begin{array}{l}55.1 \\
5.7\end{array}$ & $\begin{array}{l}224 \\
25\end{array}$ & $\begin{array}{l}1863 \\
262\end{array}$ & $\begin{array}{l}326.5 \\
27\end{array}$ & $\begin{array}{l}107.7 \\
11.6\end{array}$ & $\begin{array}{l}0.168 \\
0.046\end{array}$ & $\begin{array}{l}2.71 \\
0.19\end{array}$ & $\begin{array}{l}51.3 \\
67\end{array}$ \\
\hline
\end{tabular}

$\mathrm{W}_{\mathrm{an}}$, Peak jumping anaerobic power; $F_{\text {peak, }}$ peak jumping force; TPF, time to peak force during the pushing phase; $v_{\text {peak, }}$ peak jumping velocity.

Electro, Kempele, Finland). Five second intervals were selected $(0.2 \mathrm{~Hz})$.

\section{Blood sampling and determination of blood lactate concentration}

Blood samples were collected 3.5 minutes after $\mathrm{VO}_{2} \mathrm{MAX}$ and after the Bangsbo tests. The $20 \mu \mathrm{l}$ samples of capillary blood were withdrawn from an earlobe with Microzym micropipettes. They were stored in tubes containing $180 \mu \mathrm{l}$ of a haemolytic solution to ensure preservation of the samples at room temperature. Blood lactate concentration was subsequently measured by an enzymatic method (Microzym L; Setric Génie Industriel, Toulouse, France).

\section{Statistical analysis}

Values are expressed as mean (SD). For comparison between groups, we used a two way analysis of variance. The Scheffé statistic was used to calculate post hoc $\mathrm{p}$ values of possible difference between groups. A Pearson correlation matrix was performed between the variables of the field and laboratory tests. A stepwise linear regression analysis was used when appropriate. Statistical significance was fixed at $\mathrm{p}<0.05$.

\section{RESULTS}

No positional differences for any of the physiological variables were observed and the mean data for all players are therefore presented.

\section{Laboratory testing}

During treadmill testing, the oxygen uptake levelled off despite increased running speed in all players-that is, the true $\mathrm{VO}_{2} \mathrm{MAX}$ was determined (table 1). Table 2 presents vertical jump height variables.

\section{Field testing}

The mean (SD) time for the $30 \mathrm{~m}$ sprint test was 1.87 (0.10) seconds with a $10 \mathrm{~m}$ lap time of $4.38(0.18)$ seconds $(\mathrm{n}=30)$. Table 3 presents data from the Bangsbo field test.

\section{Correlations between laboratory and field testing}

There was no significant correlation between the Bangsbo test and $\mathrm{VO}_{2} \mathrm{MAX}$. However, there was a positive correlation between $v \mathrm{VO}_{2} \mathrm{MAX}$, vpeak $\mathrm{VO}_{2} \mathrm{MAX}$, and distance covered in the Bangsbo test (fig 2).
There was no significant correlation between vertical jump height and sprint performance (table 4). However, the peak jumping velocity and force correlated positively with $20 \mathrm{~m}$ and $30 \mathrm{~m}$ sprinting performances (table 4 ), and $46 \%$ of the $30 \mathrm{~m}$ sprinting performance was explained by the jumping force $(\mathrm{N} / \mathrm{kg})$ and jumping velocity.

\section{DISCUSSION}

This study shows that the performance in the Bangsbo test did not correlate significantly with $\mathrm{VO}_{2} \mathrm{MAX}$ in young soccer players. This was surprising as an average running intensity of $95 \%$ of maximal heart rate normally corresponds to $\mathrm{VO}_{2} \mathrm{MAX}$ when running is continuous. ${ }^{23}$ The nature of the Bangsbo test is intermittent running, and the heart rate achieved is probably not a good picture of the actual exercise intensity, as it normally takes one minute of continuous running to reach an exercise intensity corresponding to $95 \%$ of maximal heart rate. ${ }^{3}$ Therefore the exercise during the 15 seconds of high intensity running probably corresponds to an anaerobic exercise intensity beyond $\mathrm{VO}_{2} \mathrm{MAX}$. This is confirmed by the high concentration of blood lactate measured (table 3). However, the soccer players in this study represent a homogeneous group with regard to $\mathrm{VO}_{2} \mathrm{MAX}$, and therefore a correlation between the performance in the Bangsbo test and $\mathrm{VO}_{2} \mathrm{MAX}$ may be found in a more heterogeneous group of players. Heart rate values during the present Bangsbo test are similar to previous reports, ${ }^{1}$ confirming high heart rate responses to the test. Furthermore, the venous blood lactate concentrations are in accordance with those of Mujika et al, ${ }^{12}$ but higher than reported by Bangsbo and Lindquist ${ }^{7}$ and Bangsbo. ${ }^{1}$ The senior Tunisian squad $(\mathrm{n}=25)$ that participated in the 2002 African Cup and World Championships had a mean blood lactate concentration of 14.84 (1.31) $\mathrm{mmol} / \mathrm{l}$ (range 12.6-17) and covered a distance of 1879.1 (123.7) $\mathrm{m}$ in the Bangsbo test with a heart rate of 186.5 (9.9) beats/min.

The fact that the Bangsbo test correlates with the lowest and highest running speed associated with $\mathrm{VO}_{2} \mathrm{MAX}$ is surprising because normally there is a close relation between $\mathrm{VO}_{2} \mathrm{MAX}$ and running speed on an inclined treadmill. ${ }^{23}$ Testing of $\mathrm{VO}_{2} \mathrm{MAX}$ normally requires an inclined treadmill, ${ }^{23}$ and therefore perhaps the true $\mathrm{VO}_{2} \mathrm{MAX}$ was not reached in our study using a flat treadmill. However, all the criteria for reaching $\mathrm{VO}_{2} \mathrm{MAX}$ were achieved by all subjects, and we therefore conclude that the true $\mathrm{VO}_{2} \mathrm{MAX}$ was reached. Thus the relation between running speed and $\mathrm{VO}_{2} \mathrm{MAX}$ may be different when a flat treadmill is used rather than an inclined treadmill. Running technique probably plays a more prominent role when the former is used. As it has been shown in several studies ${ }^{325}$ that $\mathrm{VO}_{2} \mathrm{MAX}$ is a very important variable of match performance of soccer players, tests other than the Bangsbo test are required to either estimate or directly measure it. Helgerud et $\mathrm{al}^{3}$ showed that improving $\mathrm{VO}_{2} \mathrm{MAX}$ by $11 \%$ induces a $20 \%(\sim 1800 \mathrm{~m})$ increase in the distance covered in a match, 23\% increase in involvement with the ball, and $100 \%$ increase in the number of sprints performed. The importance of increasing the performance in the Bangsbo test on a player's match performance is still uncertain. A

\begin{tabular}{|c|c|c|c|c|c|c|}
\hline & \multirow[b]{3}{*}{ Distance $(\mathrm{m})$} & \multicolumn{4}{|l|}{ Heart rate } & \multirow{3}{*}{$\begin{array}{l}\text { Peak }\left[\mathrm{La}^{-}\right] \\
(\mathrm{mmol} / \mathrm{I})\end{array}$} \\
\hline & & \multicolumn{2}{|l|}{ Average } & \multicolumn{2}{|l|}{ Peak } & \\
\hline & & Beats/min & \%HRMAX & Beats/min & \%HRMAX & \\
\hline $\begin{array}{l}\text { Mean } \\
S D\end{array}$ & $\begin{array}{l}1830.9 \\
1238\end{array}$ & $\begin{array}{l}181 \\
6\end{array}$ & $\begin{array}{l}94.5 \\
3.3\end{array}$ & $\begin{array}{l}189 \\
5\end{array}$ & 98.9 & $\begin{array}{l}9.0 \\
37\end{array}$ \\
\hline
\end{tabular}



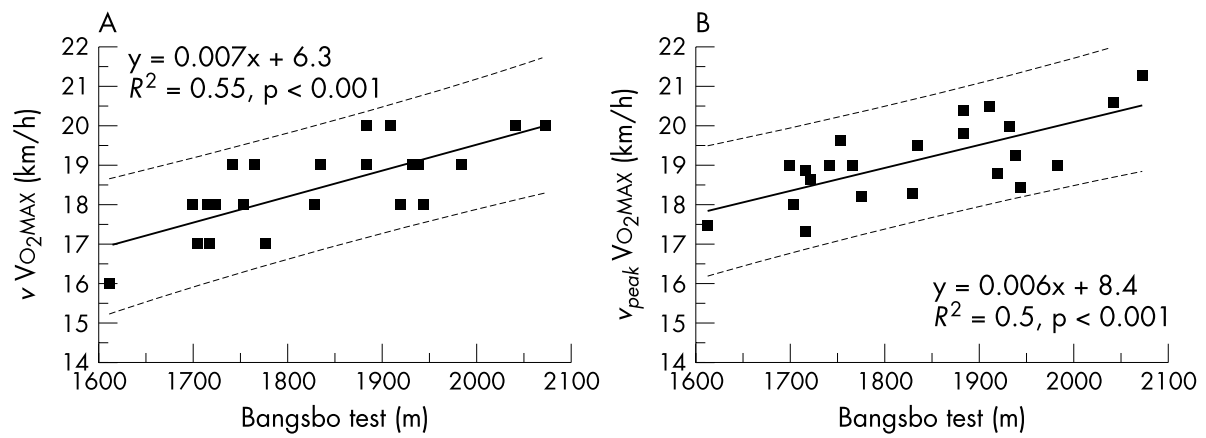

Figure 2 Relation between distance covered in the Bangsbo test and the lowest velocity corresponding to maximal oxygen uptake $\left(v \mathrm{VO}_{2} \mathrm{MAX}\right)(\mathrm{A})$ and peak velocity at $\mathrm{VO}_{2} \mathrm{MAX}$ (vpeakVO $\mathrm{O}_{2} \mathrm{MAX}$ ) (B). Dotted lines represent $95 \%$ estimation interval.

complementary study to determine the effect of a training induced increase in the Bangsbo test on match performance (distance covered, number of sprints, involvement with the ball), aerobic function $\left(\mathrm{VO}_{2} \mathrm{MAX}\right)$, and aerobic performance $\left(v \mathrm{VO}_{2} \mathrm{MAX}\right.$, time to exhaustion at $v \mathrm{VO}_{2} \mathrm{MAX}$, and running economy) would extend our knowledge of this often used test. Although the mean data show that $55 \%$ of the performance in the Bangsbo test can be explained by $v \mathrm{VO}_{2} \mathrm{MAX}$, the precision when individual values are estimated is not very accurate-that is, the standard error of the $y$ estimate is quite large (fig $2 \mathrm{~A}$ ). For example, if a player has a $v \mathrm{VO}_{2} \mathrm{MAX}$ of $18 \mathrm{~km} / \mathrm{h}$, fig $2 \mathrm{~A}$ shows that the estimated distance covered in the Bangsbo test is $1700-1950 \mathrm{~m}$; the corresponding data for $19 \mathrm{~km} / \mathrm{h}$ and $17 \mathrm{~km} / \mathrm{h}$ are 1750 $1950 \mathrm{~m}$ and $1700-1800 \mathrm{~m}$ respectively. So on an individual basis this is not very impressive. Therefore, before this test is used in a standard test battery, more studies to determine its practical use should be performed. The optimum soccer specific test has yet to be defined, and, for the time being, the most useful tests for evaluating strength and endurance training are laboratory tests. However, the Bangsbo test is useful for looking at other aspects of aerobic endurance performance besides the traditional $\mathrm{VO}_{2} \mathrm{MAX}$, running economy, and anaerobic threshold-for example, $v \mathrm{VO}_{2} \mathrm{MAX}$ and vpeak $\mathrm{VO}_{2} \mathrm{MAX}$. On the other hand, the usefulness of increasing $v \mathrm{VO}_{2} \mathrm{MAX}$ and vpeak $\mathrm{VO}_{2} \mathrm{MAX}$ without increasing $\mathrm{VO}_{2} \mathrm{MAX}$ has yet to be defined.

The values obtained for $\mathrm{VO}_{2} \mathrm{MAX}$ and anaerobic threshold in this study are of the same order as found for elite junior players in Norway. ${ }^{3}$ With the present knowledge of the importance of a high $\mathrm{VO}_{2} \mathrm{MAX}$ on match performance, further emphasis should be placed on increasing that. There is no reason for elite junior players to have a lower $\mathrm{VO}_{2} \mathrm{MAX}$ than elite senior players, approaching $70 \mathrm{ml} / \mathrm{kg} / \mathrm{min}$ (corresponding to $205 \mathrm{ml} / \mathrm{kg}^{0.75} / \mathrm{min}$ for a $75 \mathrm{~kg}$ player). ${ }^{15}$ Effective exercise training regimens, with or without the ball, have been presented in detail elsewhere, ${ }^{2}{ }^{3}$ and include periods of four minutes at an exercise intensity corresponding to 90$95 \%$ of maximal heart rate. Such a training regimen could be expected to increase $\mathrm{VO}_{2} \mathrm{MAx}$ by $0.5 \%$ per training session. ${ }^{3}$
As a soccer player jumps on average 15.5 times, with about nine headers a match, ${ }^{1}$ and performs a sprint about every 90 seconds, each lasting two to four seconds, ${ }^{126}$ jumping and sprinting performance obviously influence the outcome of a game. The $30 \mathrm{~m}$ sprint time did not significantly correlate with vertical jump height, but rather with peak velocity during the jump. This is not surprising as it has been shown that it is the level of maximal strength and the rate of force development that influence both jump height and sprint performance. ${ }^{24}{ }^{27}$ This is in accordance with previous studies in Norwegian senior elite soccer players ${ }^{13}$ and emphasises the fact that muscular force and power are relevant variables with respect to sprinting performance. Surprisingly, the $10 \mathrm{~m}$ lap time did not correlate with any of the vertical jump variables, which contrasts with previous reports. ${ }^{13}$ It must be emphasised that subjects in the latter study were adult elite players and that half of the population studied performed regular high intensity strength training, which was not the case for the players in this study. As suggested by Wisløff et $a,^{13}$ when subjects with different training regimens are studied, clearly the correlation between sprinting and jumping performance may be different. The role of age could not be ruled out either, with possible different physiological capacities ${ }^{17}$ and/or lower level of acceleration skills. The jumping performance in the present study was in the normal range for soccer players. ${ }^{315}$ The sprint results fit in with observations in elite junior players in a previous study. ${ }^{3}$ The $10 \mathrm{~m}$ lap time could give important information, as indicated by the substantial differences within the $30 \mathrm{~m}$ test, with some of the subjects having similar $30 \mathrm{~m}$ times but notably different $10 \mathrm{~m}$ times. In this context, it must be emphasised that the $10 \mathrm{~m}$ performance is a relevant test variable in modern soccer. Cometti et $a l^{16}$ have shown that French professional and amateur soccer players had similar $30 \mathrm{~m}$ sprint performances but the professionals had significantly lower $10 \mathrm{~m}$ lap times.

\section{Conclusions}

In young soccer players, the Bangsbo test and $30 \mathrm{~m}$ sprint test correlate with $v \mathrm{VO}_{2} \mathrm{MAX}$ and peak jumping velocity

Table 4 Correlation between vertical jump variables and the $20 \mathrm{~m}$ (from 10 to $30 \mathrm{~m}$ ) and $30 \mathrm{~m}$ sprint performances

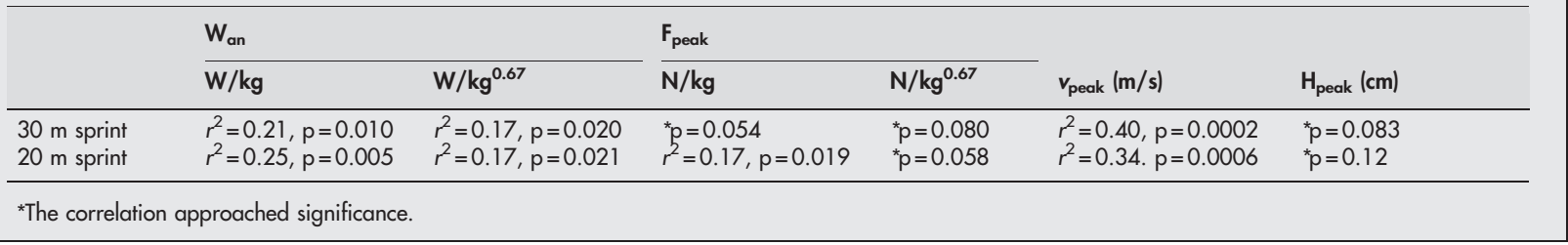




\section{Take home message}

The Bangsbo test, which is used to assess endurance of soccer players, correlates with $v \mathrm{VO}_{2} \mathrm{MAX}$ but does not provide a good estimate of $\mathrm{VO}_{2} \mathrm{MAX}$ in young soccer players. The $30 \mathrm{~m}$ sprint performance correlates with the velocity and force variables measured during vertical jumping.

respectively. The Bangsbo test does not give a good estimate of $\mathrm{VO}_{2} \mathrm{MAX}$, and further studies are necessary to determine its practical use in a test battery for soccer players.

\section{ACKNOWLEDGEMENTS}

In memory of Dorra. We thank the coaches, Skander Kasri and Gilbert Zoonekynd, for their collaboration, Hatem Ziadia, Gaby Mkaouar, and Hajer Amri for their technical support, and Drs Zakia Bartagi, Noureddine Zerzri, Fethi Kaouech, Mourad Kaouech, and Wajdi Dardouri for their valuable help.

\section{Authors' affiliations}

K Chamari, Y Hachana, Y B Ahmed, F Sghaïer, National Centre of Sports Medicine, El Menzah, Tunisia

O Galy, O Hue, Laboratoire ACTES, UFR-STAPS Antilles-Guyane, Pointe à Pitre, France

J-C Chatard, Laboratoire GIP Exercice, St Etienne, France

U Wisloff, Department of Circulation and Medical Imaging, Norwegian University of Science and Technology, and Department of Cardiology, St Olavs Hospital, Trondheim, Norway

\section{REFERENCES}

1 Bangsbo J. The physiology of soccer-with special reference to intense intermittent exercise. Acta Physiol Scand 1994;15(suppl 619):1-156.

2 Hoff J, Wisløff $U$, Engen LC, et al. Soccer specific aerobic endurance training. Br J Sports Med 2002;36:218-21.

3 Helgerud J, Engen LC, Wisløff U, et al. Aerobic endurance training improves soccer performance. Med Sci Sports Exerc 2001;33:1925-31.

4 Léger LA, Mercier D, Gadoury C, et al. The multistage 20 metre shuttle run test for aerobic fitness. J Sports Sci 1988;6:93-101.

5 Léger L, Boucher R. An indirect continuous running multistage field test: the Université de Montreal track test. Can J Appl Sport Sci 1980;5:77-84.

6 Kemi OJ, Hoff J, Engen LC, et al. Soccer specific testing of maximal oxygen uptake. J Sports Med Phys Fitness 2003;43:139-44.
7 Bangsbo J, Lindquist F. Comparison of various exercise tests with endurance performance during soccer in professional players. Int J Sports Med 1992;13:125-32.

8 Bangsbo J. Tests de terrain pour footballeurs. Actualites Sport et Medicine 1995:38:3-8.

9 Nicholas CW, Nuttall FE, Williams C. The Loughborough intermittent shuttle test: a field test that simulates the activity of soccer. J Sports Sci 2000;18:97-104.

10 Bangsbo J. Fitness training in football. A scientific approach. Bagsvaerd, Denmark: Ho+Storm, 1994:88-97.

11 Reilly T, Bangbso J, Franks A. Anthropometric and physiological predispositions for elite soccer. J Sports Sci 2000;18:669-83.

12 Mujika I, Padilla S, Ibañez J, et al. Creatine supplementation and sprint performance in soccer players. Med Sci Sports Exerc 2000;32:518-25.

13 Wisløff U, Castagna C, Helgerud J, et al. Strong correlation of maximal squat strength with sprint performance and vertical jump height in elite soccer players. Br J Sports Med 2004;38.

14 Grassi B, Cerretelli P, Narici MV, et al. Peak anaerobic power in master athletes. Eur J Appl Physiol 1991;62:394-9.

15 Wisloff U, Helgerud J, Hoff J. Strength and endurance of elite soccer players. Med Sci Sports Exerc 1998;30:462-7.

16 Cometti G, Maffiuletti NA, Pousson M, et al. Isokinetic strength and anaerobic power of elite, subelite and amateur French soccer players. Int J Sports Med $2001 ; 22: 45-51$.

17 Hansen L, Bangsbo J, Twisk J, et al. Development of muscle strength in relation to training level and testosterone in young male soccer players. J Appl Physiol 1999;87:1141-7.

18 Whipp BJ, Ward SA, Lamarra N, et al. Parameters of ventilatory and gas exchange dynamics during exercise. J Appl Physiol 1982;52:1506-13.

19 Billat VL, Koralsztein JP. Significance of the Velocity at $\mathrm{VO}_{2 \max }$ and time to exhaustion at this velocity. Sports Med 1996;22:90-108

20 Paavolaïnen L, Häkkinen K, Hämäläinen I, et al. Explosive-strength training improves $5-\mathrm{km}$ running time by improving running economy and muscle power. J Appl Physiol 1999;86:1527-33.

21 Beaver WL, Wasserman K, Whipp BJ. A new method for detecting anaerobic threshold by gas exchange. J Appl Physiol 1986:60:2020-7.

22 Bergh U, Sjødin B, Forsberg A, et al. The relationship between body mass and oxygen uptake during running in humans. Med Sci Sports Exerc 1991;23:205-11.

23 Åstrand PO, Rodahl K. Texbook of work physiology. New York: McGraw-Hill, 2003.

24 Hoff J, Berdahl GO, Bråten S. Jumping height development and body weight considerations in ski jumping. In: Müller E, Schwameder $\mathrm{H}$, Raschner $\mathrm{C}$, et al, eds. Science and skiing II. Hamburg: Verlag Dr Kovac, 2001:403-12.

25 Apor P. Successful formulae for fitness training. In: Reilly T, Less A, Davids K, et al, eds. Science and football. London: E \& FN Spon, 1988:95-107.

26 O'Donoghue P. Time-motion analysis of work rate in elite soccer. In: Notational analysis of sport IV. Porto: M.H.a.F. Tavares. Centre for team sports studies, Faculty of Sport Sciences and Physical Education, University of Porto, 2001:65-70.

27 Schmidtbleicher D. Training for power events. In: Komi $P$, ed. Strength and power in sport. London: Blackwell Scientific Publications, 1992:381-95. 